Short Communication

\title{
Testing the monophyly of Aesculus L. and Billia Peyr, woody genera of tribe
}

\section{Hippocastaneae of the Sapindaceae}

AJ Harris ${ }^{1,2}$ : Oklahoma State University, Department of Botany, 301 Physical Sciences, Stillwater, Oklahoma 74078, USA

Chengxin Fu: Zhejiang University, College of Life Sciences, Hangzhou, 310058, China

Qiu-Yun (Jenny) Xiang: North Carolina State University, Department of Plant and Microbial

Biology, 2115 Gardner Hall, Campus Box 7612, Raleigh, North Carolina 27695, USA

LaRinda Holland ${ }^{3}$ : Oklahoma State University, Department of Botany, 301 Physical Sciences, Stillwater, Oklahoma 74078, USA

Jun Wen: National Museum of Natural History, Department of Botany, MRC 166, Smithsonian Institution, Washington, DC 20013-7012, USA

${ }^{1}$ Author to whom correspondence should be addressed·aj.harris@inbox.com

${ }^{2}$ Present Address: National Museum of Natural History, Department of Botany, MRC 166, Smithsonian Institution, Washington, DC 20013-7012, USA MRC 166, Washington, D.C. 20013, USA

${ }^{3}$ Present address: Oklahoma State University, Oklahoma Animal Disease Diagnostic Laboratory, West Farm Road, Stillwater, Oklahoma 74078, USA 


\begin{abstract}
Hippocastaneae is a well-supported clade in Sapindaceae that comprises $15+$ species; $12+$ in Aesculus, two in Billia, and one in Handeliodendron Rehder. The monophyly of Aesculus and Billia were widely assumed, but a recent molecular phylogenetic study of Sapindanceae used seven species of Aesculus and one each of Billia and Handeliodendron and showed that Billia and Handeliodendron were nested within Aesculus. Here, we tested the hypothesis that Aesculus and Billia are mutually monophyletic using phylogenetic analyses of seven molecular markers and 31 accessions of Hippocastaneae representing 14 species. We performed phylogenetic analyses using a dataset of concatenated genes as well as with coalescent method for constructing a species tree from individual gene trees. The analysis of seven concatenated markers and the species tree strongly supported the mutual monophyly of Aesculus and Billia. We also recovered support for the traditional arrangement of genera within Hippocastaneae: Aesculus and Billia comprising a clade that is sister to Handeliodendron. However, the relationships among the genera remain incompletely resolved.
\end{abstract}

Keywords: Aesculus, Billia, Handeliodendron, Hippocastaneae, phylogeny, Sapindaceae 


\section{Introduction}

Morphological and molecular evolutionary studies show that the woody plant genera, Aesculus L. (i.e., buckeyes and horsechestnuts), Billia Peyr., and Handeliodendron Rehder should be regarded as a distinct tribe, Hippocastaneae (Acevedo-Rodriguez et al., 2011), within a broadly circumscribed Sapindaceae (Buerki et al., 2009; Buerki et al., 2010; Gadek et al., 1996; Harrington et al., 2009; Harrington et al., 2005; Judd et al., 1994). Aesculus, (12+ spp.) Billia (2 ssp.) and the monotypic Handeliodendron formerly comprised the family Hippocastanaceae (Fang, 1960, 1981; Hardin, 1957a, b, c, 1960; Turland and Xia, 2005, 2007). Handeliodendron was originally circumscribed within the tribe Harpullieae of Sapindaceae (Rehder, 1935) butwas later resolved in clade with Aesculus and Billia based on phylogenetic analyses of morphological characters (Judd et al., 1994). The three genera of Hippocastaneae are distinguished within Sapindanceae by having opposite leaves, connate sepals (tubular or campanulate), and seven stamens (individuals rarely with more or less) (Hardin, 1957c; Jussieu, 1789; Lawrence, 1951; Rehder, 1935). However, they share 4- and 5-merous flowers, pollen in monads, and the lack of endosperm in common with other sapindaceous taxa (Acevedo-Rodriguez et al., 2011). Hippocastaneae is sister to Acereae, which comprises Acer L. (i.e., maples) and Dipteronia Oliv. (Acevedo-Rodriguez et al., 2011)

The polytypic genera in Hippocastaneae, Aesculus and Billia, are traditionally assumed to be mutually monophyletic (Acevedo-Rodriguez et al., 2011; Hardin, 1957a, b, c, 1960; Takhtajan, 2009; Turland and Gadek, 2007; Xia et al., 2007) and to comprise a clade that is sister to Handeliodendron (Judd et al., 1994; Xiang et al., 1998). However, a recent molecular phylogenetic study (Buerki et al., 2010) used eight sparsely sampled markers for nine species of Hippocastaeae and showed Billia and Handeliodendron nested within Aesculus. Nevertheless, 
that study and other prior molecular studies on Hippocastaneae have either included too few species of Aesculus and Billia to evaluate their monophyly (Buerki et al., 2009; Buerki et al., 2011; Harrington et al., 2005) or have hardwired Billia and Handeliodendron as monophyletic outgroups (Harris et al., 2009; Xiang et al., 1998).

The primary objective of this study was to test the hypothesis that Aesculus and Billia are mutually monophyletic. We tested our hypothesis using phylogenetic reconstructions based on rigorous taxonomic sampling and seven molecular markers including chloroplast and nuclear genes. We also used our data to assess the relationships among Aesculus, Billia, and

\section{Handeliodendron.}

\section{Materials and Methods}

\subsection{Taxonomic Sampling}

We sampled 23 accessions of Aesculus representing 11 of $12+$ species (including two subspecies each within A. glabra Willd. and A. pavia L.), six accessions of Billia representing 2 species and an unidentified individual, and two accessions of Handeliodendron bodinieri Rehder. Unfortunately, we were unable to sample Aesculus assamica Griff., which occurs in western China, Myanmar, and the Assam region in India (Hardin, 1960). However, A. assamica may be synonymous with Aesculus wangii Hu (Turland and Xia, 2007), which we did sample. We also sampled five species of Acer L. representing five traditional taxonomic sections (van Gelderen et al., 1994). We treated Acer within the ingroup in phylogenetic analyses to reaffirm the monophyly of Hippocastneae. Our sampling comprised other species of Sapindaceae as outgroups: Koelreuteria bipinnata Franch., Sapindus L. sp. and Ungnadia speciosa Endl. All accessions are documented by herbarium collections, and we have provided voucher information in Table 1. 


\subsection{Molecular Data}

\subsubsection{Generating Molecular Data}

We obtained DNAs from leaf materials that were either freshly collected and dried in silica gel or removed with permission from herbarium specimens at the United States National Herbarium (US). For the freshly collected and herbarium materials, we followed identical procedures for DNA extraction. We prepared the materials for extraction by freezing them in liquid nitrogen and grinding them into powder using a bead mill. We accomplished the extractions using manufacturer protocols for an Autogen Gene Prep robot (AutoGen, Inc., Holliston, MA, USA), which automates the CTAB extraction method (Doyle and Doyle, 1987).

We amplified DNA from seven molecular markers with priming sites broadly conserved in angiosperms and representing five chloroplast and two nuclear DNA (cpDNA and nDNA, respectively) regions. Our cpDNA markers comprised the open reading frame of $y c f 1$ (Dong et al., 2015) and the intergenic spacers pet $\mathrm{N}-\operatorname{trn} \mathrm{C}$ (Lee and Wen, 2004), $\operatorname{trn} \mathrm{S}-\operatorname{trn} \mathrm{G}$ (Shaw et al., 2005), $\operatorname{trn} \mathrm{L}-\operatorname{trn} \mathrm{F}$ (Taberlet et al., 1991), and $p s b \mathrm{~A}-\operatorname{trn} \mathrm{H}$ (Sang et al., 1997). We amplified the chloroplast gene regions (or genes, hereafter) using the primers detailed in the cited studies. Our nDNA markers were composed of portions of the third exon and intron of at 103 and the second intron of $s q d 1$ using primers reported by Li et al. (2008). Our PCR reactions for all primer pairs comprised 2.5 $\mu \mathrm{L}$ of PCR Buffer, $2.0 \mu \mathrm{L}$ of $10 \mathrm{mM}$ dNTPs, $50 \mathrm{mM}$ of $\mathrm{MgCl}_{2}, 1.0 \mu \mathrm{L}$ each of forward and reverse primers, $0.5 \mu \mathrm{L}$ of BSA, $0.2 \mu \mathrm{L}$ of Taq Polymerase, and $14.05 \mu \mathrm{L}$ of nuclease free water; and we performed PCR reactions under thermocycler conditions of initiation at $95^{\circ} \mathrm{C}$ for $5 \mathrm{~min}$; 35 cycles of $94^{\circ} \mathrm{C}$ for $45 \mathrm{~s}, 54^{\circ} \mathrm{C}$ for $45 \mathrm{~s}\left(52^{\circ} \mathrm{C}\right.$ for $\left.\operatorname{trn} \mathrm{L}-\operatorname{trn} \mathrm{F}\right)$, and $72^{\circ} \mathrm{C}$ for $45 \mathrm{~s}$; and a final extension at $72^{\circ} \mathrm{C}$ for $10 \mathrm{~min}$. We purified the amplified PCR products using the ExoSapIT 
enzyme with activation at $37^{\circ} \mathrm{C}$ and deactivation at $95^{\circ} \mathrm{C}$. We attempted to amplify and sequence each gene for all plant materials collected for this study.

We used the purified PCR products and PCR primers to perform cycle sequencing. Our PCR products were small, so internal primers were unnecessary. We prepared the sequencing reactions using standard Big Dye (Applied Biosystems, Foster City, USA) protocols except that we used $0.8 \mu \mathrm{L}$ of enzyme and brought the reaction to $10 \mu \mathrm{L}$ volume with water. The cycle sequencing comprised 30 thermocycles of $95^{\circ} \mathrm{C}$ for $30 \mathrm{~s}, 50^{\circ} \mathrm{C}$ for $30 \mathrm{~s}$, and $60^{\circ} \mathrm{C}$ for 4 minutes. The products of cycle sequencing were read by an ABI 3730 automated sequencer (Applied Biosystems, Foster City, USA). All sequences were new to this study (Table 1).

\subsubsection{Processing and Analyzing Molecular Sequence Data}

We assembled DNA sequences using algorithms in Geneious version 7.1.5 (Kearse et al., 2012) and Mesquite version 2.75 (Maddison and Maddison, 2011). Specifically, we used Geneious to remove blocks of low quality bases ( $\geq 5 \%$ chance of error per base) at the $3^{\prime}$ and $5^{\prime}$ ends of sequencing results and, subsequently, to generate contigs of sequences for each marker for each accession. We edited base calls as needed by eye from chromatograms and allowed ambiguous nucleotide character states. We used the Geneious global alignment algorithm with a gap penalty of 12, extension cost of three, and free end gaps to align sequences of all taxa for each gene. We allowed the alignment algorithm to run for ten iterations beyond to the first one for refinement. We adjusted the alignments manually in Mesquite to minimize gaps.

For each aligned gene, we found the best models of nucleotide evolution using JModelTest version 2.1.4 (Posada, 2008). We compared a total of 203 models including those with a gamma distribution of rates $(+G)$ approximated by ten categories and a proportion of 
invariant sites (+I). We set JModelTest to calculate the best model according to the Bayesian information criterion (BIC) to limit overfitting (i.e., compared to AIC, see Hastie et al., 2005).

To reduce missing data in matrices for each gene, we trimmed the ends of sequences and applied indel coding. We trimmed the sequences so that neither the $5^{\prime}$ or $3^{\prime}$ ends of a matrix had more than $20 \%$ missing data. We applied indel coding to a concatenated matrix of all sequences only. Our indel coding comprised the simple, binary method of Simmons and Ochoterena(2000), implemented in SeqState (Müller, 2005).

We performed phylogenetic analyses using MrBayes version 3.2.2 (Ronquist et al., 2012) on the Cowboy supercomputer maintained by Oklahoma State University High Performance Computing Center (https://hpcc.okstate.edu/). These analyses consisted of two simultaneous runs for each gene independently, for concatenated matrices of chloroplast and nuclear genes independently, and for a concatenated matrix of all DNA data. We set the analyses to implement the model parameters resolved with JModelTest, and we used the best fitting model among those that MrBayes can implement (Table 2). The best models for all genes included a gamma rate distribution, which we approximated with ten rate categories. We ran our analyses in MrBayes with 11 hot chains and 1 cold chain for 15 million MCMC generations with sampling every 5000 generations (i.e., 3001 trees). For the analyses of the concatenated matrices, we partitioned the data by gene and unlinked the model parameters among partitions. We checked all runs visually for stationarity using Tracer version 1.6 (Rambaut and Drummond, 2007), and we determined that a $20 \%$ burnin was appropriate for all posterior distributions of trees. We implemented the burnin and combined the trees from the simultaneous runs using LogCombiner from the *BEAST package. 
We performed coalescent analyses in *BEAST (Drummond and Rambaut, 2007) using three different datasets to generate species trees. Our datasets comprised (1) all seven genes partitioned individually, (2) all genes partitioned by organelle (chloroplast and nuclear), and (3) nuclear genes only partitioned individually. For all three datasets, we assigned each accession to its species, except that we removed Billia sp. from the matrix, because we could not determine with confidence whether it belonged to B. hippocastanum or B. rosea (see Table 1).

Additionally, we treated the three outgroups as a single species represented by three sequences. In treating the outgroups in this way, we followed Heled and Drummond (2010); namely in that 'species' in the coalescent analysis refers to a lineage that ceased to interbreed with the rest of the group in the past, not a taxonomic rank. Moreover, using an outgroup represented by multiple sequences enabled a more rigorous implementation of the *BEAST tree building algorithm, because multiple sequences of a taxon are required to estimate its coalescent events and population size (Heled and Drummond, 2010). We implemented substitution models as shown in Table 2 with gamma categories set to ten and applied a random local molecular clock with no calibrations independently for each gene. We also set the birth-death model for speciation rates across the tree and modeled population size as piecewise and linear with a constant root. We started phylogenetic estimation in *BEAST with a UPGMA tree for each gene partition, and we ran *BEAST for ten million generations with sampling every 1000 generations for a total posterior distribution represented by ten thousand species trees. We checked the *BEAST results in Tracer, and manually removed $20 \%$ of trees as burnin. We performed the *BEAST analyses on the Cowboy supercomputer.

We generated maximum credibility trees for all post-burnin distributions of trees, including species trees, using TreeAnnotator, which is part of the *BEAST package. We set 
TreeAnnotator to calculate the maximum credibility trees using only posterior probabilities of $\geq 0.5$ and with the node heights of clades representing the median of the posterior distribution. We visualized the maximum credibility trees using FigTree version 1.4.2 (http://tree.bio.ed.ac.uk/software/figtree/).

We performed a NeighborNet network analysis in SplitsTree version 4.13.1 (Huson, 1998) for Hippocastaneae using DNA sequences from all genes. We performed the network analysis as a preliminary way to detect and visualize reticulate evolution, such as arises due to hybridization. There is no evidence for ongoing hybridization among Aesculus, Billia, and Handeliodendron, and they are probably too geographically separated for it to occur. Nevertheless, we cannot rule out ancient hybridization, especially because some species of Aesculus produce natural hybrids in areas of secondary contact or when cultivated in close proximity to one other (Hardin, 1957d). Within SplitsTree, we used the NeighborNet method because, it allows and graphs groupings that are incompatible in bifurcating phylogenies (Huson and Bryant, 2006). For performing the NeighborNet analysis, we calculated distances between sequences in SplitsTree as the proportion of different sites (Huson and Bryant, 2006), and we removed sequences of two accessions that resulted in reciprocally saturated distances (i.e., of 1 due to differentially missing data; Billia hippocastanum 2 and Billia hippocastanum 5 and additional information in Table 1). We determined the support for the splits in the network using 1000 bootstrap replicates. We drew the network in SplitsTree using the Equal Angle algorithm, which improves visual clarity by graphing parallel (i.e., non-crossing) edges, or branches (Kloepper and Huson, 2008).

\section{Results and Discussion}

\subsection{Phylogenetic Analyses}




\subsubsection{Single-Gene Phylogenies}

Our phylogenetic analyses of individual genes yielded mixed results for the monophyly of Billia and Aesculus (Table 3). Five of the seven genes supported the monophyly of Billia (1.00pp), while psbA-trnH showed that Billia was paraphyletic and included Handeliodendron (0.36pp), and sqd1 showed that Billia formed a grade into Aesculus (Table 3). The monophyly of Aesculus was supported by two chloroplast genes with $\mathrm{pp}=1.00$. However, Aesculus was paraphyletic and included Billia and Handeliodendron according the other three chloroplast genes and both nuclear genes. The paraphyly in Aesculus had weak support $(\mathrm{pp}=0.12-0.79)$. All single gene trees are presented in Supplementary file 1.

Among individual genes, phylogenetic positions were highly variable for A. californica (Spach.) Nutt, which is endemic to California and southern Oregon, A. parviflora Walt., which occurs narrowly in Alabama and Georgia, and members of sect. Calothyrsus, which have ranges within mainland eastern Asia. For example, A. californica was sister to sect. Calothyrsus in the $p s b \mathrm{~A}-t r n \mathrm{H}$ tree and sister to sect. Aesculus, comprising species disjunct in Japan and Europe, in the pet $\mathrm{N}-\operatorname{trn} \mathrm{C}$ tree. The positions of A. californica, A. parviflora, and sect. Calothyrsus have also been inconsistent among prior studies (Forest et al., 2001; Hardin, 1957c; Harris et al., 2009; Xiang et al., 1998). In particular, A. californica was resolved within or as sister to sect. Calothyrsus according to cladistic analyses of cpDNA and morphology, but it is sister to $A$. parviflora according to published nuclear phylogenies (Forest et al., 2001; Hardin, 1957c; Harris et al., 2009; Xiang et al., 1998). The sister relationship of A. californica to A. parviflora may also be supported inductively by biogeography, because species pairs may be less likely to be disjunct among continents (i.e., Asia and North American) than more distantly related clades within genera (Wen, 1999). The inconsistent relationships among A. californica, A. parviflora, and sect. 
Calothyrsus may be due to incomplete lineage sorting (Harris et al., 2009; Xiang et al., 1998) or ancient hybridization. In our present analyses, these three species behaved as wildcards (sensu Nixon and Wheeler, 1992) by occupying many weakly supported positions within and among the posterior distributions of gene trees, and they may have reduced support for or interfered with other nodes in our phylogeny (Nixon and Wheeler, 1992). Further work is needed to stabilize the phylogenetic positions of A. californica, A. parviflora, and sect. Calothyrsus; especially with greater taxonomic sampling depth within these three lineages to test hypotheses of incomplete lineage sorting and hybridization.

\subsubsection{Chloroplast and Nuclear Gene Phylogenies}

We obtained different results from our analyses of the cp- and nuclear DNA. The concatenated cpDNA matrix resolved the monophyly of Aesculus and Billia: Aesculus comprised a clade with $1.00 \mathrm{pp}$ and Billia had $0.99 \mathrm{pp}$. In contrast to the cpDNA, the concatenated nuclear DNA matrix yielded a topology in which Aesculus contained independent clades of Billia and Handelidendron (Table 3; trees not shown). Paraphyly within the nuclear gene tree may result from the wildcard behavior of A. californica and A. parviflora, which were sister, respectively, to Billia, and a clade of sect. Aesculus, Billia, and A. parviflora. In the coalescent analysis of nuclear genes only, we resolved Billia with 1.00pp but found only 0.09pp for Aesculus (Fig. S1A).

\subsubsection{Total Evidence Analyses (Concatenated Matrix, Species Tree, Network)}

We performed total evidence analyses of concatenated data matrices with and without indel coding. Both analyses yielded the same topology and highly similar branch lengths. Thus, we present and discuss the tree with indel, because it showed equal or slightly higher pp values at all nodes. 
All total evidence analyses supported the monophyly of Aesculus and Billia. The analysis of concatenated data resulted in monophyletic clades of Aesculus and Billia each with 1.00pp. While this result must be regarded with caution, because concatenation can amplify either phylogenetic signal or noise (Gadagkar et al., 2005), it is corroborated by our two coalescent analyses of all genes (Fig. S1B-C). The coalescent analysis with partitioning by gene yielded species trees with 1.00pp for the monophyly both genera (Fig. S1B), and the analysis with partitioning by organelle resulted in 0.91pp for Aesculus and 1.00pp for Billia (Fig. S1C). The monophyly of both genera is corroborated by evidence from pollen, which is larger in Billia than in all of Aesculus according to prior studies (Harris et al., 2015; also see Pozhidaev, 1995). Additionally, our network analysis showed that Aesculus and Billia formed relatively well supported, distinct groups with bootstrap support of $81.6 \%$ and 100\%, respectively (Fig. S2).

Among genera, we found support for a clade of Aesculus and Billia with Handeliodendron as its sister in all phylogenetic analyses except the coalescent analysis with nuclear genes only. Specifically, Aesculus and Billia were sisters in our analysis of the concatenated data matrix with 0.89pp (Fig. 1). The clade of Aesculus and Billia was also resolved in the coalescent analyses of all genes partitioned individually (0.67pp; Fig. S1B) and by organelle (0.41pp; Fig. S1C). The sister relationship between Aesculus and Billia may be corroborated by prior morphological studies, which unite the two genera and separate them from Handeliodendron on the basis of leaflets without glandular spots, anthers with apical and basal appendages (apical only in Handeliodendron), petals without appendages or appendages minute, and having a sessile ovary (Acevedo-Rodriguez et al., 2011; Judd et al., 1994; Xia et al., 2007). However, the coalescent analysis of nuclear genes only showed Aesculus as sister to Handeliodendron ( $\mathrm{pp}=0.50$; Fig. A). Aesculus and Handelidendron also exhibit shared traits 
including habitats that are within temperate latitudes and leaves with three to 11 leaflets in contrast to Billia, which occurs in the tropics and bears leaves with three leaflets (Hardin, 1957; Manchester, 2001; Xia et al., 2007). Overall, our support for the relationships among Aesculus, Billia, and Handeliodendron is relatively weak.

\subsection{Summary}

Aesculus and Billia are mutually monophyletic based on our analyses of all seven genes using traditional Bayesian and coalescent methods. However, phylogenies based on single genes or combined nuclear genes suggested weak support for the paraphyly of the two genera, especially Aesculus. We speculate that the paraphyly of Aesculus was an artifactual result of noise in our posterior distribution of trees caused by A. californica, A. parviflora, and members of sect. Calothyrsus, which seemed to behave as wildcards in phylogenetic analyses. Our results low support for Aesculus as sister to Billia within Hippocastaneae. Nevertheless, the relationships among Aesculus, Billia, and Handeliodendron still need to be more completely resolved in future work with more robust data such as more plastid and nuclear genes.

\section{Acknowledgements}

We gratefully acknowledge Xue Yang, a visiting scientist at the Smithsonian National Museum of Natural History (NMNH) from Kunming University, and Gabriel Johnson of the NMNH for assistance in the molecular laboratory. We are equally indebted to Yunjuan Zuo of Shanghai Chengshan Botanical Garden for her advice on our network analysis. For their assistance in obtaining plant materials for study, we sincerely thank T'ai Roulston of State Arboretum of Virginia, Shannon Smith of San Antonio Botanical Garden, Helen Smisko of Rancho Santa Ana Botanic Garden, Mark Weathington of JC Raulston Arboretum, Ari Novy and Kyle Wallick of United States Botanic Garden, Richard Olsen of United States National Arboretum, and Jan 
McSwain of the Morrison Oklahoma Tree Board. Sue Lutz and Melinda Peters, both of the NMNH, provided important assistance in accessioning and annotating voucher specimens. This study represents one outcome of a Smithsonian Graduate Student Fellowship at the NMNH awarded to Harris in 2014, and laboratory work for this project was partially supported by the NMNH Laboratories of Analytical Biology of the Smithsonian Institution. 


\section{References}

Acevedo-Rodriguez, P., Welzen, P.C.v., Adema, F., Ham, R.W.J.M.v.d., 2011. Sapindaceae. In: Kubitzki, K. (Ed.), Flowering Plants. Eudicots: Sapindales, Cucurbitales, Myrtaceae. Springer, New York, pp. 357-407.

Buerki, S., Forest, F., Acevedo-Rodríguez, P., Callmander, M.W., Nylander, J.A.A., Harrington, M., Sanmartín, I., Küpfer, P., Alvarez, N., 2009. Plastid and nuclear DNA markers reveal intricate relationships at subfamilial and tribal levels in the soapberry family (Sapindaceae). Mol. Phylogenet. Evol. 51, 238-258.

Buerki, S., Forest, F., Alvarez, N., Nylander, J.A.A., Arrigo, N., Sanmartín, I., 2011. An evaluation of new parsimony-based versus parametric inference methods in biogeography: a case study using the globally distributed plant family Sapindaceae. J. Biogeogr. 38, 531-550.

Buerki, S., Lowry, P., Alvarez, N., Razafimandimbison, S.G., Küpfer, P., Callmander, M.W., 2010. Phylogeny and circumscription of Sapindaceae revisited: molecular sequence data, morphology and biogeography support recognition of a new family, Xanthoceraceae. Plant Ecol. and Evol. 143, 148-159.

Dong, W., Xu, C., Li, C., Sun, J., Zuo, Y., Shi, S., Cheng, T., Guo, J., Zhou, S., 2015. ycf1, the most promising plastid DNA barcode of land plants. Sci. Rep. 5, 8348.

Doyle, J.J., Doyle, J.L., 1987. A rapid DNA isolation procedure for small quantities of fresh leaf tissue. Phytochem. Bull. 19, 11-15.

Drummond, A., Rambaut, A., 2007. BEAST: Bayesian evolutionary analysis by sampling trees. BMC Evol. Biol. 7, 214.

Fang WP. 1960. Additamenta ad floram sinensem I. Hippocastanaceae. Acta Sci. Nat.Univ. Szechuan 1960: 77-125. 
Fang WP. 1981. Hippocastanaceae. In: Flora Reipublicae Popularis Sinicae, Vol. 46. Beijing:

Science Press. 274-289.

Forest, F., Drouin, J.N., Charest, R., Brouillet, L., Bruneau, A., 2001. A morphological

phylogenetic analysis of Aesculus L. and Billia Peyr. (Sapindaceae). Can. J. Bot. 79, 154-169.

Gadagkar, S.R., Rosenberg, M.S., Kumar, S., 2005. Inferring species phylogenies from multiple genes: Concatenated sequence tree versus consensus gene tree. J. Exp. Zool. B Mol. Dev. Evol. 304B, 64-74.

Gadek, P.A., Fernando, E.S., Quinn, C.J., Hoot, S.B., Terrazas, T., Sheahan, M.C., Chase, M.W., 1996. Sapindales: Molecular delimitation and infraordinal groups. Am. J. Bot. 83, 802-811

Hardin, J.W., 1957a. A Monogaphic Study of the American Hippocastanaceae. University of Michigan, Ann Arbor, p. 216.

Hardin, J.W., 1957b. A revision of the American Hippocastanaceae. Brittonia 9, 145-171.

Hardin, J.W., 1957c. A revision of the American Hippocastanaceae-II. Brittonia 9, 173-195.

Hardin, J.W., 1957d. Studies in the Hippocastanaceae, IV. Hybridization in Aesculus. Rhodora $59,185-203$.

Hardin, J.W., 1960. Studies in the Hippocastanaceae, V. Species of the Old World. Brittonia 12, 26-38.

Harrington, M.G., Biffin, E., Gadek, P.A., 2009. Comparative study of the evolution of nuclear ribosomal spacers incorporating secondary structure analyzes within Dodonaeoideae, Hippocastanoideae and Xanthoceroideae (Sapindaceae). Mol. Phylogen. Evol. 50, 364-375. Harrington, M.G., Edwards, K.J., Johnson, S.A., Chase, M.W., Gadek, P.A., Manos, P.S., 2005. Phylogenetic Inference in Sapindaceae sensu lato using Plastid matK and $r b c \mathrm{~L}$ DNA sequences. Syst. Bot. 30, 366-382. 
Harris, AJ, Lutz, S., Acevedo, P., Wen, J., 2015. The utility of the morphological variation of pollen for resolving the evolutionary history of Billia (subfam. Hippocastanoideae, Sapindaceae). Journal of Systematics and Evolution 53, 228-238.

Harris, AJ., Xiang, Q.-Y., Thomas, D.T., 2009. Phylogeny, origin, and biogeographic history of Aesculus L. (Sapindales) an update from combined analysis of DNA sequences, morphology, and fossils. Taxon 58, 108-126.

Hastie, T., Tibshirani, R., Friedman, J., Franklin, J., 2005. The elements of statistical learning: data mining, inference and prediction. The Mathematical Intelligencer 27, 83-85.

Heled, J., Drummond, A.J., 2010. Bayesian inference of species trees from multilocus data. Mol. Biol. Evol. 27, 570-580.

Huson, D.H., Bryant, D., 2006. User Manual for SplitsTree4 V4.6. p. 58.

Judd, W., Sanders, R., Donoghue, M., 1994. Angiosperm family pairs: preliminary phylogenetic analyses. Harv. Pap. Bot. 5, 1-51.

Jussieu, A.-L., 1789. Genera Plantarum. In: Cramer, J., Weinheim (Eds.), Historiae Naturalis Classica, Tomus XXXV. Wheldon \& Wesley, Ltd., New York, p. 498.

Kearse, M., Moir, R., Wilson, A., Stones-Havas, S., Cheung, M., Sturrock, S., Buxton, S., Cooper, A., Markowitz, S., Duran, C., Thierer, T., Ashton, B., Meintjes, P., Drummond, A., 2012. Geneious Basic: An integrated and extendable desktop software platform for the organization and analysis of sequence data. Bioinformatics 28, 1647-1649.

Kloepper, T.H., Huson, D.H., 2008. Drawing explicit phylogenetic networks and their integration into SplitsTree. BMC Evol. Biol. 8, 1-7.

Lawrence, G.H.M., 1951. Taxonomy of Vascular Plants. The Macmillan Company, New York. 
Lee, C., Wen, J., 2004. Phylogeny of Panax using chloroplast $\operatorname{trnC}-\operatorname{trn} \mathrm{D}$ intergenic region and the utility of $\operatorname{trn} \mathrm{C}-\operatorname{trn} \mathrm{D}$ in interspecific studies of plants. Mol. Phylognet. Evol. 31, 894-903. Li, M., Wunder, J., Bissoli, G., Scarponi, E., Gazzani, S., Barbaro, E., Saedler, H., Varotto, C., 2008. Development of COS genes as universally amplifiable markers for phylogenetic reconstructions of closely related plant species. Cladistics 24, 727-745.

Maddison, W.P., Maddison, D.R., 2011. Mesquite: A modular system for evolutionary analysis. Manchester, S.R., 2001. Leaves and fruits of Aesculus (Sapindales) from the Paleocene of North America. Int. J. of Plant Sci. 162, 985-998

Müller, K., 2005. SeqState. Applied bioinformatics 4, 65-69.

Nixon, K.C., Wheeler, Q.D., 1992. 4: Extinction and the origin of species. In: Novacek, M.J., Wheeler, Q.D. (Eds.), Extinction and Phylogeny. Columbia University Press, New York, pp. 119-143.

Posada, D., 2008. jModelTest: Phylogenetic model averaging. Mol. Biol. Evol. 25, 1253-1256.

Rambaut, A., Drummond, A., 2007. Tracer.

Rehder, A., 1935. Handeliodendron, a new genus of the Sapindaceae. J. Arnold Arbor. 16, 6568.

Ronquist, F., Teslenko, M., van der Mark, P., Ayres, D.L., Darling, A., Höhna, S., Larget, B., Liu, L., Suchard, M.A., Huelsenbeck, J.P., 2012. MrBayes 3.2: efficient Bayesian phylogenetic inference and model choice across a large model space. Syst. Biol. 61, 539-542.

Sang, T., Crawford, D., Stuessy, T., 1997. Chloroplast DNA phylogeny, reticulate evolution, and biogeography of Paeonia (Paeoniaceae). Am. J. Bot. 84, 1120. 
Shaw, J., Lickey, E.B., Beck, J.T., Farmer, S.B., Liu, W., Miller, J., Siripun, K.C., Winder, C.T., Schilling, E.E., Small, R.L., 2005. The tortoise and the hare II: relative utility of 21 noncoding chloroplast DNA sequences for phylogenetic analysis. Am. J. Bot. 92, 142-166.

Simmons, M.P., Ochoterena, H., 2000. Gaps as characters in sequence-based phylogenetic analyses. Sys. Biol. 49, 369-381.

Taberlet, P., Gielly, L., Pautou, G., Bouvet, J., 1991. Universal primers for amplification of three non-coding regions of chloroplast DNA. Plant Mol. Biol. 17, 1105-1109.

Takhtajan, A., 2009. Flowering Plants. Springer.

Turland, N.J., Gadek, P.A., 2007. Handeliodendron. In: Wu, Z.Y., Raven, P.H., Hong, D.Y. (Eds.), Flora of China. Vol. 12 (Hippocastanaceae through Theaceae). Missouri Botanical Garden Press, St. Louis.

Turland, N.J., Xia, N., 2005. A new combination in Chinese Aesculus (Hippocastanaceae). Novon 15, 488-489.

Turland, N.J., Xia, N., 2007. Aesculus. In: Wu, Z.Y., Raven, P.H., Hong, D.Y. (Eds.), Flora of China. Vol. 12 (Hippocastanaceae through Theaceae). Missouri Botanical Garden Press, St. Louis.

van Gelderen, D.M., Jong, P.C., Oterdoom, H.J., Dudley, T.R., 1994. Maples of the World. Timber Press.

Wen, J., 1999. Evolution of the eastern Asian and eastern North American disjunct distributions in flowering plants. Annu. Rev. Ecol. Syst. 30, 421-455.

Xia, N., Turland, N.J., Gadek, P.A., 2007. Hippocastanaceae. In: Wu, Z.Y., Raven, P.H., Hong, D.Y. (Eds.), Flora of China. Vol. 12 (Hippocastanaceae through Theaceae). Missouri Botanical Garden Press, St. Louis. 
Xiang, Q.-Y., Crawford, D.J., Wolfe, A.D., Tang, Y.-C., DePamphilis, C.W., 1998. Origin and biogeography of Aesculus L. (Hippocastanaceae): A molecular phylogenetic perspective. Evolution 52, 988-997. 
Table 1: Taxonomic and molecular sampling of Aesculus, Billia, Handeliodendron, and outgroups (all other genera). Subscripted numerals to the right of taxon names differentiate between multiple accessions where necessary and correspond to numbered accessions appearing in trees. For voucher specimens, we give the collector and collection number. All voucher specimens are housed at US unless otherwise noted by a parenthetical herbarium acronym. Symbols: ${ }^{\ddagger}$ Vouchered by an herbarium specimen with accession number 797498 at RSA; \#Vouchered by an additional herbarium specimen with accession number 4552 at the unregistered herbarium of the State Arboretum of Virginia. Numbers beneath marker names refer to Genbank accession numbers. Genbank does not accept sequences of length <200, so some sequence fragments can be obtained only via Treebase (submission 19364; http://purl.org/phylo/treebase/phylows/study/TB2:S19364?x-access-code=e098844e0bb7703fdee93a378c80aed3\&format=html FOR REVIEWER ACCESS ONLY). These are marked as 'see Treebase.'

\begin{tabular}{|c|c|c|c|c|c|c|c|c|}
\hline \multirow{4}{*}{$\begin{array}{l}\text { Taxon } \\
\text { Acer cappadocicum Gled. var. } \\
\text { sinicum Rehder } \\
\text { Acer negundo L. }\end{array}$} & \multirow{3}{*}{$\begin{array}{l}\text { Collector and number } \\
\text { Wen } 12548\end{array}$} & \multicolumn{7}{|c|}{ Molecular markers } \\
\hline & & at103 & $s q d 1$ & $p s b \mathrm{~A}-t r n \mathbf{H}$ & $\operatorname{trn} \mathbf{C}-p e t \mathbf{N}$ & $\operatorname{trn} \mathrm{L}-t r n \mathrm{~F}$ & trnS-trnG & $y c f 1$ \\
\hline & & - & KX277877 & KX277794 & KX277763 & KX277731 & KX277824 & KX277906 \\
\hline & Wen 12532 & KX277851 & - & KX277800 & - & KX277732 & KX277829 & KX277907 \\
\hline Acer palmatum Thunb. & Wen 12523 & KX277852 & KX277878 & KX277812 & KX277768 & KX277733 & KX277830 & KX277908 \\
\hline Acer saccharinum $\mathrm{L}$. & Wen 12540 & KX277853 & KX277879 & KX277814 & KX277767 & KX277734 & KX277828 & KX277909 \\
\hline Acer triflorum Kom. & Wen 12544 & KX277854 & KX277880 & KX277818 & KX277765 & KX277735 & KX277826 & KX277910 \\
\hline Aesculus californica (Spach.) Nutt. & Harris 2014-13 & KX277855 & KX277881 & KX277795 & KX277781 & - & KX277841 & KX277911 \\
\hline Aesculus chinensis ${ }^{1}$ Bunge & Wen 12550 & KX277856 & KX277882 & - & KX277762 & - & KX277823 & KX277912 \\
\hline Aesculus chinensis ${ }^{2}$ Bunge & Harris 2014-14 & KX277857 & KX277883 & KX277811 & KX277780 & KX277736 & KX277840 & KX277913 \\
\hline Aesculus flava ${ }^{1}$ Aiton & Wen 12543 & KX277858 & KX277884 & KX277797 & KX277766 & KX277737 & KX277827 & KX277914 \\
\hline Aesculus flava ${ }^{2}$ Aiton & Harris 2014-07 & - & KX277885 & - & KX277786 & - & KX277845 & KX277915 \\
\hline $\begin{array}{l}\text { Aesculus glabra Willd. var. arguta }{ }^{1} \\
\text { (Buckley) B.L. Rob. }\end{array}$ & Harris 2014-18 & KX2778 & KX277886 & KX277817 & KX277776 & KX277738 & KX277837 & see Treebase \\
\hline
\end{tabular}


Aesculus parryi Gray

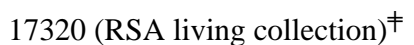

Aesculus parviflora ${ }^{1}$ Walter

\section{Wen 12546}

Wen 12702

Aesculus pavia L. var. flavescens ${ }^{1}$

Harris 2014-16

(Sarg.) Correll

Aesculus pavia $\mathrm{L}$. var. flavescens ${ }^{2}$

Harris 2014-17

(Sarg.) Correll

Aesculus pavia L. var. pavia ${ }^{1}$

Harris 2014-01

Aesculus pavia L. var. pavia ${ }^{2}$

Harris 2014-08

Aesculus sylvatica ${ }^{1}$ Bart.

Aesculus sylvatica ${ }^{2}$ Bart.

Aesculus turbinata Blume

Aesculus wangii $\mathrm{Hu}$

Aesculus wilsonii ${ }^{1}$ Rehder

Aesculus wilsonii ${ }^{2}$ Rehder

Billia hippocastanum ${ }^{2}$ Peyr

Billia hippocastanum ${ }^{3}$ Peyr

Billia hippocastanum ${ }^{4}$ Peyr

Billia hippocastanum ${ }^{5}$ Peyr

Harris 2014-04 \#

Wen 12592

Harris 2014-15

Wen 12482

Harris 2012-01

Wen 12470

D.E. Wilbur and R.L. Stone 8669

S.S. Tillett 636-40

Gorostiza s.n.

Castillo 2055

Billia rosea ${ }^{1}$ (Planch. \& Linden) C. Jaramillo 7880

Ulloa \& P. Jørg.

Billia Peyr. sp.

Handeliodendron bodinieri ${ }^{1}$ Rehder

Handeliodendron bodinier $i^{2}$ Rehder

Koelreuteria bipinnata Franch.

Xiang 1186 (NSC)

Xiang 1193 (NSC)

Wen 12495

Wen 12485

Ungnadia speciosa Endl.

Harris s.n.

KX277887

KX2778

see Treebase

KX277861

KX277862

KX277863

see Treebase

KX277864

KX277865

KX277866

see Treebase

KX277867

$-$

see Treebase

KX277868

KX277869

see Treebase

see Treebase

KX277870

KX277871

see Treebase

see Treebase

see Treebase

KX277872

KX277873

KX277874

KX277875

KX277876
KX277888

KX277889

KX277890

KX277891

KX277892

KX277893

KX277894

KX277895

KX277896

KX277897

KX277898

KX277899

KX277900

KX277901

KX277902

-

KX277903

see Treebase

see Treebase

see Treebase

see Treebase

KX277904

KX277905
KX277810

see Treebase

-

KX277809

KX277796

KX277804

KX277806

KX277807

KX277802

KX277793

see Treebase

-

KX277799

KX277798

KX277801

KX277816

KX277813

KX277808

KX277805$$
\text { - }
$$

-

see Treebase

see Treebase

KX277815

KX277803

KX277819
KX277782

KX277760

KX277784

KX277783

KX277764

KX277759

KX277778

KX277777

KX277788

KX277785

KX277787

KX277761

KX277779

KX277771

KX277789

KX277772

KX277773

KX277790

-

KX277774

see Treebase

KX277757

KX277758

KX277769

KX277770

KX277775
KX277739

KX277740

-

KX277741

KX277742

KX277743

KX277744

KX277745

KX2777

KX277747

KX277748

KX277749

-

KX27775

-

$-$

KX27775

-

-

KX277752

KX277753

KX277754

KX277755

KX277756
KX277842

KX277822

KX277844

KX277843

KX277850

KX277825

KX277821

KX277838

$-$

KX277847

-

KX277846

KX277839

KX277833

KX277848

KX277834

-

KX277835

KX277849

KX277931

see Treebase

KX277820

KX277831

KX277832

KX277836
KX277932

KX277933

KX277934

KX277917

KX277918

KX277919

KX277920

KX277921

KX277922

KX277923

KX277924

KX277925

KX277926

KX277927

KX277928

KX277929

KX277930

-

-

KX277935 
Table 2: Information and statistics for our sequences of at 103, psbA-trnH, pet $\mathrm{N}-\operatorname{trn} \mathrm{C}$, sqd1, trn L-trnF, trnS-trnG, and $y c f 1$. 'All' refers to all sequences, whereas 'tribe' refers to the sequences of species of Aesculus, Billia, and Handeliodendron. The 'best model' is the model with the highest likelihood according to the Bayesian information criterion, while the 'model used' has the highest likelihood among models available in MrBayes. In *BEAST, we used the HKY model in place of the simpler models, which are marked with asterisks (*).

\begin{tabular}{|c|c|c|c|c|c|c|c|c|c|c|c|c|}
\hline \multirow[t]{2}{*}{ Marker } & \multicolumn{2}{|c|}{ \# taxa } & \multirow[t]{2}{*}{ best model } & \multirow[t]{2}{*}{ model used } & \multirow[t]{2}{*}{$\begin{array}{c}\text { average } \\
\text { unaligned } \\
\text { length }\end{array}$} & \multirow[t]{2}{*}{$\begin{array}{c}\text { aligned } \\
\text { length } \\
\text { with gaps } \\
\end{array}$} & \multirow[t]{2}{*}{$\begin{array}{c}\text { \# gaps } \\
\text { coded and } \\
\text { removed }\end{array}$} & \multirow[t]{2}{*}{$\begin{array}{c}\text { final } \\
\text { number of } \\
\text { characters }\end{array}$} & \multicolumn{2}{|c|}{$\begin{array}{l}\% \text { non-identical } \\
\text { nucleotide sites }\end{array}$} & \multicolumn{2}{|c|}{$\%$ missing nucleotides } \\
\hline & all & tribe & & & & & & & all & tribe & all & tribe \\
\hline at103 & 35 & 28 & $\mathrm{TVM}+\mathrm{I}+\mathrm{G}$ & $\mathrm{GTR}+\mathrm{I}+\mathrm{G}$ & 373.1 & 584 & 27 & 345 & 94.0 & 84.8 & 10.5 & 13.4 \\
\hline psbA-trnH & 31 & 23 & $\mathrm{~F} 81+1+\mathrm{G}$ & $\mathrm{F} 81+1+\mathrm{G}^{*}$ & 441.2 & 740 & 94 & 200 & 87.6 & 82.8 & 8.2 & 10.6 \\
\hline pet $\mathrm{N}-t r n \mathrm{C}$ & 35 & 28 & $\mathrm{TVM}+\mathrm{I}+\mathrm{G}$ & $\mathrm{GTR}+\mathrm{I}+\mathrm{G}$ & 626.6 & 772 & 36 & 525 & 53.2 & 27.9 & 1.7 & 1.8 \\
\hline sqd1 & 34 & 28 & $\mathrm{JC}+\mathrm{I}+\mathrm{G}$ & $\mathrm{JC}+\mathrm{I}+\mathrm{G}^{*}$ & 254.3 & 258 & 7 & 258 & 25.6 & 17.3 & 5.4 & 6.5 \\
\hline trnL-trnF & 26 & 18 & $\mathrm{JC}+\mathrm{I}+\mathrm{G}$ & $\mathrm{JC}+\mathrm{I}+\mathrm{G}^{*}$ & 887.3 & 1047 & 58 & 310 & 39.6 & 17.0 & $<0.1$ & 0.0 \\
\hline $\operatorname{trnS-trnG}$ & 33 & 25 & $\mathrm{HKY}+\mathrm{I}+\mathrm{G}$ & $\mathrm{HKY}+\mathrm{I}+\mathrm{G}$ & 752.1 & 1025 & 98 & 400 & 80.0 & 19.6 & 5.8 & 3.8 \\
\hline$y c f 1$ & 30 & 23 & $\mathrm{TrN}+\mathrm{I}+\mathrm{G}$ & $\mathrm{HKY}+\mathrm{I}+\mathrm{G}$ & 756.4 & 816 & 34 & 742 & 44.1 & 24.5 & 2.9 & 3.7 \\
\hline
\end{tabular}


Table 3: Summary of independent Bayesian phyloegnetic analyses of seven genes and combined nuclear and chloroplast genes,

respectively, showing posterior probability (pp) support values for the monophyly of Aesculus and Billia. We indicate monophyly by showing the pp support. In cases where the genera were not monophyletic, we present notes and the pp for the most highly supported node that rejects monophyly.

\begin{tabular}{lcc}
\hline \hline Marker & \multicolumn{1}{c}{ Aesculus } & Billia \\
\hline at103 & $\mathrm{pp}=0.55 ;$ includes Billia and Handeliodendron & 1.00 \\
psbA-trnH & $\mathrm{pp}=0.56 ;$ includes Billia and Handeliodendron & $\mathrm{pp}=0.36$;includes Handeliodendron \\
pet $\mathbf{N}-$ trnC & 1.00 & 0.99 \\
sqd1 & $\mathrm{pp}=0.14 ;$ includes Handeliodendron & $\mathrm{pp}=0.20 ;$ Billia grades into Aesculus \\
trnL-trnF & $\mathrm{pp}=0.06 ;$ includes Billia and Handeliodendron & NA -1 sample \\
trnS-trnG & $\mathrm{pp}=0.79 ;$ includes Billia and Handeliodendron & 1.00 \\
ycf1 & 1.00 & $\mathrm{NA}-1$ sample \\
combined cpDNA & 1.00 & 0.99 \\
combined nDNA & $\mathrm{pp}=0.12 ;$ includes Billia and Handeliodendron & 1.00 \\
\hline \hline
\end{tabular}




\section{Figure Captions}

FIG. 1. Total evidence, maximum credibility phylograms resulting from Bayesian analysis of seven molecular markers A - with and B - without use of indel coding. Clades of Aesculus, Billia, and Handeliodendron are delimited with gray boxes. The tree is rooted with Ungnadia speciosa, Sapindus sp., and Koelreuteria bipinnata, and these outgroups are indicated by their

genus names only. Other genus names are abbreviated, and Ae. represents Aesculus, while Ac. represents Acer. We show pp support on nodes. Nodes marked with asterisks (*) have pp values of 1.00, and unmarked nodes have pp values of 1.00 or less. 


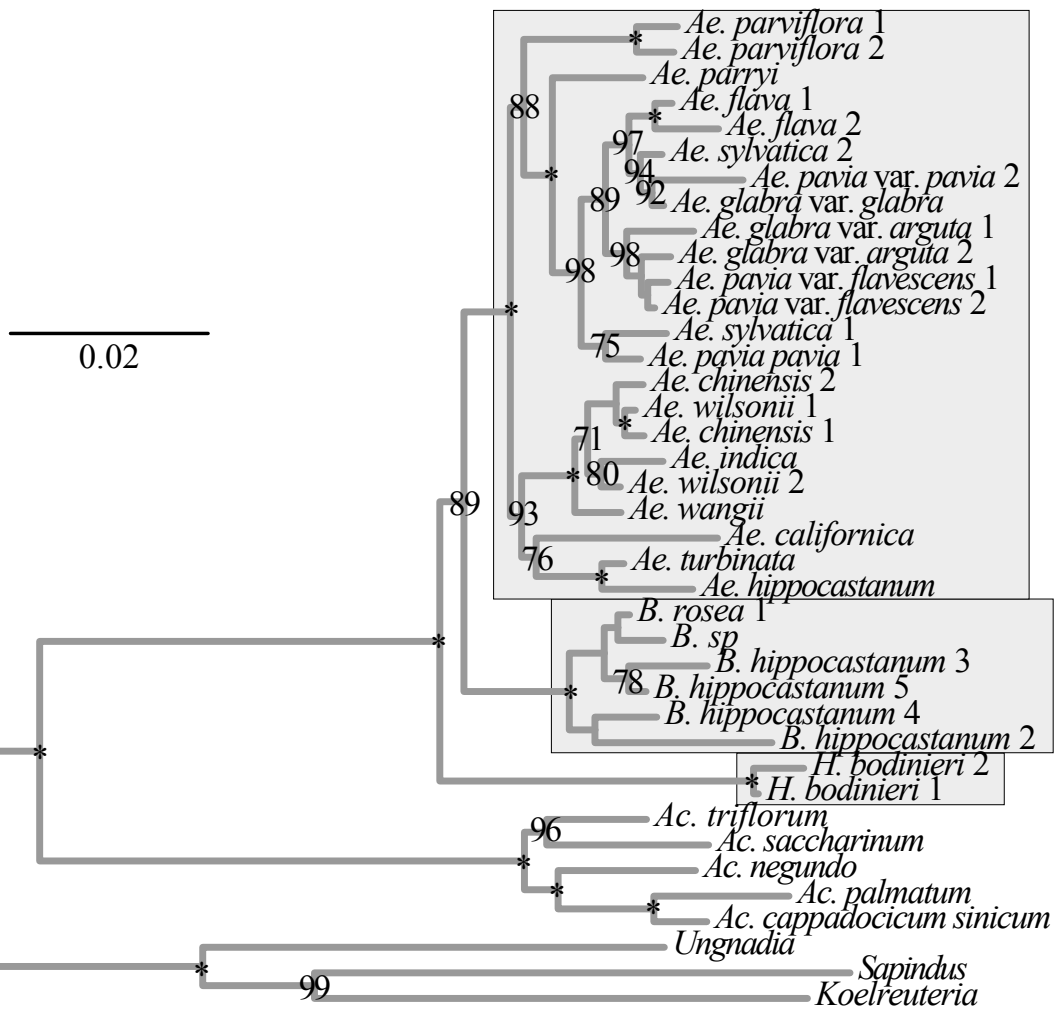




\section{*Graphical Abstract}

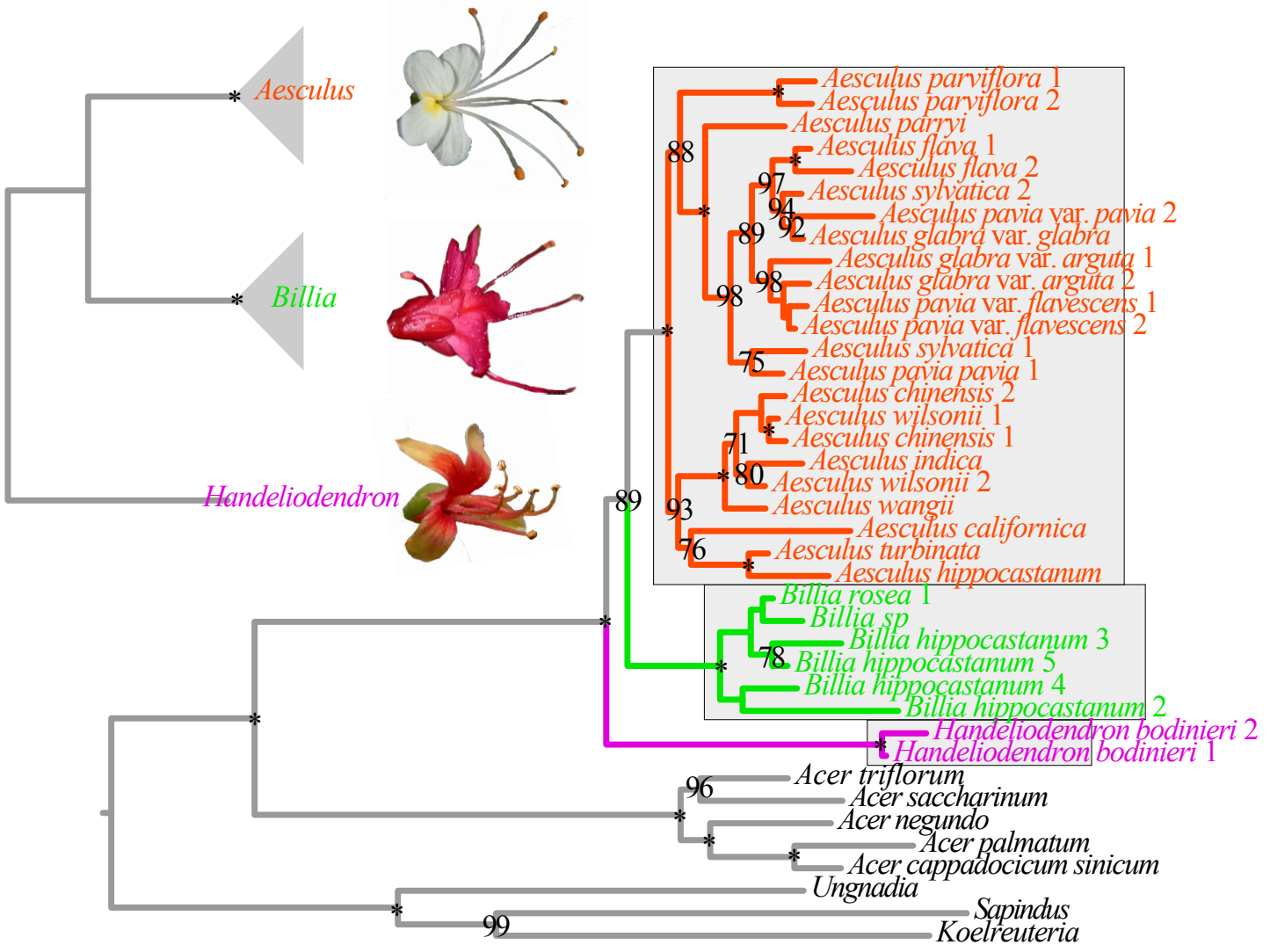

